\title{
A study on heavy metal sorption properties of intestinal microbiota in vitro
}

\author{
Alexey Sizentsov ${ }^{1}$, Yaroslav Sizentsov ${ }^{1}$, Olga Kvan $^{1,2}$, Elena Salnikova ${ }^{1}$, Valeriya Salnikova ${ }^{1}$ \\ ${ }^{1}$ Orenburg State University, 460000, 13 Pobedy pr, Orenburg, Russia \\ ${ }^{2}$ Federal State Scientific Institution «Federal Research Centre of Biological Systems and Agro-technologies of the Russian Academy \\ of Sciences»; Federal State Budgetary Educational, Russia, Orenburg, 9 Yanvarya, 29
}

\begin{abstract}
Water and soil pollution by heavy metals has led to their accumulation in the ground and waters, to a sharp decline of ecosystem biopotential, and to foodstuff contamination, resulting in internal pollutions in bodies of humans and animals with food, air, water. In this regard, the purpose of our study was to examine the impact of heavy metals on the growth of representatives of rats' intestinal microbiota and to estimate sorption characteristics of these microorganisms. The research was conducted in three stages: i) a study of essential and xenobiotic elements' biotoxicity; ii) their impact on the growth of the microbiota in periodic cultivation; and iii) studying bioaccumulative characteristics. In the research, we discovered that all investigated organisms had pronounced resistance to lead and iron, which was confirmed by the results of the evaluating the impact on the growth and the accumulating characteristics of the studied microorganisms (more than $50 \%$ ). The strain of E. faecium has the most pronounced sorption characteristics - its level of accumulation amounted for iron $-63.3 \%$, lead $-61 \%$, zinc $-38.4 \%$, copper $-11.4 \%$, and cadmium $-33.2 \%$, minimum values were obtained in samples of L. acidophilus, which sorbed these elements in concentrations of $46.2 \%, 42.3 \%, 10.3 \%, 3.8 \%$, and $5.3 \%$, respectively.
\end{abstract}

\section{Introduction}

All microorganisms, as well as any other living organisms, require certain heavy metals such as cobalt, manganese, iron, copper, zinc as components of nutrition. With that, some metal ions are essential for microorganisms.

There are two variants of metal ions localization: so, some elements (such as copper) are associated mainly with the cell surface, other elements (f.e., mercury and iron), inpour into cells. There are bacteria and fungi that produce special chelating substances to facilitate the iron penetration into a cell at neutral $\mathrm{pH}$. This penetration occurs as a result of the active chelate iron transport and chelate dissolution after transferring it through the plasma membrane. Even the toxic arsenate ion can permeate into a cell by means of the active transport, like in the case of Saccharomyces cerevisiae [1].

When examining the patterns of the interaction of heavy metals with microorganisms, toxic effects of heavy metal ions on microorganisms should also be taken into account.

There are several mechanisms of heavy metal toxic effects on microorganisms. Firstly, heavy metal ions can play the role of antimetabolites, resulting in the inhibition of certain biochemical processes, accompanied by violation of the cell functions and inhibition of cell growth. Secondly, heavy metal ions can form a stable precipitation (or chelates) with important metabolites or catalyze the decay of such metabolites, so that they become unavailable to the cells. Thirdly, heavy metal ions are capable of replacing structurally or electrochemically important elements, which leads to disruption of enzyme or cell function [2].

It is known that microorganisms when interacting with heavy metal ions are able to accumulate them. Total metal content in organisms increases with the rise of their content in the environment. Metals get accumulated in the cells before saturating concentrations, after that, further metal content enhancing in the environment does not increase sorption of them by cells. Accumulation of elements can last for from a few seconds to several hours.

Based on the above, we stated the goal to explore the influence of heavy metals on the growth of representatives of rats' intestinal microbiota and to estimate sorption characteristics of the microorganisms.

\section{Materials and methods}

For the realization of the study, we previously selected and identified representatives of intestine normal flora using the methods of pure cultures, macromorphological and tinctorial population properties, test-systems and Hiss's serum water medium. In the study, we cultivated the following microorganisms: Escherichia coli, Enterobacter cloacae, Enterococcus faecium, Lactobacillus acidophilus. One of the main phases of our research was to assess biotoxicity of salts of essential $(\mathrm{Cu}, \mathrm{Zn}, \mathrm{Fe})$ and toxic $(\mathrm{Cd}, \mathrm{Pb})$ elements to optionally anaerobic representatives of rats' intestinal microbiota because these elements are antagonists, and their excessive presence in the body leads to a decrease in the

\footnotetext{
Corresponding author: kwan111@yandex.ru
} 
content of other elements. As xenobiotic factors of influence on the growth and sustainability of the populations, we used salts of copper $\left(\mathrm{CuSO}_{4}\right.$, $\left.\mathrm{Cu}\left(\mathrm{CH}_{3} \mathrm{COO}\right)_{2}, \mathrm{CuCl}_{2}\right)$, zinc $\left(\mathrm{ZnSO}_{4}, \mathrm{Zn}\left(\mathrm{CH}_{3} \mathrm{COO}\right)_{2}\right.$, $\left.\mathrm{ZnCl}_{2}, \mathrm{Zn}\left(\mathrm{NO}_{3}\right)_{2}\right)$, iron $\left(\mathrm{FeSO}_{4}, \mathrm{Fe}\left(\mathrm{NO}_{3}\right)_{2}, \mathrm{FeCl}_{3}\right)$, cadmium $\left(\mathrm{CdSO}_{4}, \mathrm{Cd}\left(\mathrm{CH}_{3} \mathrm{COO}\right)_{2}, \mathrm{CdCl}_{2}\right)$, and lead $\left(\mathrm{Pb}\left(\mathrm{NO}_{3}\right)_{2}, \mathrm{~Pb}\left(\mathrm{CH}_{3} \mathrm{COO}\right)_{2}\right)$ in the experiment.

To complete this phase of the work we used the methods of serial dilution and agar basins. However, in the course of work, we gave the priority to the method of agar basins, since it allows not only visually, but also a qualitative assessing the impact of lead on the growth of the microorganisms [3].

Assessment of the metal impact on the growth of the microorganisms was carried out by measuring the optical density of the microorganism suspension in the liquid nutrient medium with intervals of 3 hours to receive 3 close values that indicated the occurrence of the stationary growth phase. Based on the results of the obtained optical densities, we plotted the growth curves in periodical culture (including in the presence of toxicants) using Microsoft Excel. Each point of the growth curve represents an average of three independent experiments [4].

The final stage of our work was to determine the amount of metal accumulated by bacteria from the nutrient medium. The quantification of metal was carried out by the atomic-absorption method and biomass and supernatant were analyzed. To do this we applied the analyzed metals at working concentrations in the medium for the cultivation and began cultivation till the start of the stationary growth phase. At the end of the cultivation, the samples were processed and analyzed with atomic-absorption spectrophotometer (AASP) [3].

\section{Results}

The initial phase of our study was an assessment of biotoxicity of the studied metals composed of salts with a different anionic component in concentrations ranging from $1 \mathrm{~mol} / 1$ to $0.016 \mathrm{~mol} / \mathrm{l}$ obtained by the method of serial dilutions to the growth of the microorganisms.

The obtained from our research data indicates that there are general patterns of toxicity of both essential and toxic heavy metals. As we think, the toxicity level of biogenic elements could be associated with the lack of detoxification protective mechanisms in bacterial cells. Also, one of the possible criteria for toxicity of the studied compounds is the dissociation extent of salts in aqueous solutions.

When assessing biotoxicity of copper compounds to the studied microorganisms, we found that E. coli $(0.125$ $\mathrm{mol} / \mathrm{l}$ ) had the most pronounced resistance, other representatives of optionally anaerobic intestinal microbiota had identical values of resistance to copper salts. The sub-inhibiting concentration was $0.032 \mathrm{~mol} / \mathrm{l}$, which allows us to suppose the absence of distinct effects of an anion component on the growth of the studied microorganisms.

Analyzing the effects of anions on zinc biotoxicity, we should note that, like in the case of copper, common regularities were not revealed: so speaking of zinc sulfate, all the studied microorganisms showed identical resistance in a range of concentrations of $0.063 \mathrm{~mol} / \mathrm{l}$. The strain of $L$. acidophilus turned out to be the most sensitive to zinc acetate, for which the sub-inhibiting concentration was $0.032 \mathrm{~mol} / \mathrm{l}$, similar values of resistance for this microorganism were received in respect of action of zinc chloride and acetate.

Like in the case with the effect of copper cations on the growth of the populations, maximum resistance against iron salts was recorded for the strain of $E$. coli $\left(0.125 \mathrm{~mol} / 1-\mathrm{FeSO}_{4}, 0.063 \mathrm{~mol} / \mathrm{l}-\mathrm{Fe}\left(\mathrm{NO}_{3}\right)_{2}\right.$ and $\mathrm{FeCl}_{3}$ ). Also, it should be noted that the rest of the studied strains continued a general trend of biotoxicity regardless of the anionic component $(0.032 \mathrm{~mol} / \mathrm{l})$.

Analysis of the data shown in table 4 speaking of assessment of effects of cadmium salts composed of cations with a different anionic component testifies the marked toxic effects of this element to all representatives of the optionally anaerobic microbiota in intestines of rats.

It should be noted that the most pronounced xenobiotic effect was from cadmium chloride and acetate, their presence in the substrate at the concentration of $0.016 \mathrm{~mol} / 1$ has a sub-inhibiting effect on all the studied microorganisms, while cadmium sulfate proved to be less toxic to E. coli, E. cloacae and L. acidophilus, which growth was registered in concentrations of $0.032 \mathrm{~mol} / 1$ in the nutritious medium. For E. faecium the sub-inhibiting concentration of this compound was the same toxicity value as those of cadmium chloride and acetate.

Biotoxicity assessment of lead compounds (table 5) indicates a relatively high resistance of the studied microorganisms to this element, which, as we suppose, is associated with the activation of the detoxification mechanisms of bacterial cells in the presence of the toxic element in a nutrient medium. It should be noted that the most pronounced resistance was revealed for E. cloacae and $E$. faecium, which showed no distinct bactericidal effect in presence of lead cations in $\mathrm{Pb}\left(\mathrm{NO}_{3}\right)_{2}$ in the concentration of $0.25 \mathrm{~mol} / \mathrm{l}$. The same indicators of sustainability in the strains were obtained in the study of the toxicity of $\mathrm{Pb}\left(\mathrm{CH}_{3} \mathrm{COO}\right)_{2}$, however, the data obtained in the course of this experiment indicate the more pronounced toxic action of this compound (subinhibiting concentration $-0.125 \mathrm{~mol} / \mathrm{l}$ ).

All bacteria execute and reveal the process of accumulation of metals in the stationary growth phase. The process of accumulation is associated with the fact that during this phase the substrate is dwindling and the toxic products are accumulated, forcing the bacteria to seek for other sources of energy and detoxification of the environment. In this regard, the next stage of our work was to determine the growth phases with a view to identifying the optimal time of growth in periodic culture, as well as the influence of heavy metal salts on the growth dynamics of the studied microorganisms.

Determination of the optimal growth time in periodic culture was carried out by the cultivation of the studied strains in periodic culture in the liquid nutrient medium and measuring optical density every 3 hours, starting 
with zero hours. Measurements were conducted until we received at least three approximately equal values of optical density, indicating the beginning of a stationary growth phase. According to the results obtained for each strain, growth curves were plotted.

Generalizing the obtained data, we should note that all the studied microorganisms showed almost an identical picture of growth dynamics in the presence of metal cations in the medium in relation to the control values. However, it is important that the presence of excessive contents of lead and iron in substrate has a strong stimulating effect on all the studied microorganisms, which, in our opinion, in the case of lead, is associated with detoxification protective mechanisms, as a result of which (the accumulation of metals in an inactive form on the surface of bacterial cells) a change in the optical density of the population of microorganisms occurs, as evidenced by higher values in the phase of accelerated growth.

The presence of iron cations in the substrate has a stimulating effect on the studied strains of microorganisms, which in our view is associated with depositing characteristics of microorganisms because iron is actively involved in the enzymatic metabolic processes of bacterial cells. The presence of excessive contents of zinc and copper cations in the nutrient medium does not have any marked influence on the growth of the studied microorganisms in periodic cultivation, however, it should be noted that the presence of these elements for the majority of the studied microorganisms prolongs the time of the beginning of $\mathrm{M}$ phase of growth concentration. The pronounced negative effect on the growth of the studied microorganisms was recorded for cadmium, its present in the composition of the substrate inhibits the growth of the studied representatives of microbiota (the sub-inhibiting effect of the xenobiotic factor), but also significantly reduces the time of the logarithmic growth phase.

The final phase of this experimental part was to evaluate sorption characteristics of optionally anaerobic intestinal microbiota in rats (Figure 1).

In the research, we discovered that all the investigated organisms actively accumulate cations of lead and iron (more than 50\%), which directly correlates with the data on the determination of metal cations biotoxicity and the assessment of the impact of the metals on the growth of microorganisms studied. With that, the most pronounced accumulating effect was registered for the strain of E. faecium, which level of sorption characteristics amounted for iron $-63.3 \%$, lead - $61 \%$, zinc $-38.4 \%$, copper $-11.4 \%$, and cadmium $33.2 \%$. The minimal values were obtained in samples of L. acidophilus, which sorbed these elements in concentrations of $46.2 \%, 42.3 \%, 10.3 \%, 3.8 \%$, and $5.3 \%$, respectively.

The maximum values of the accumulation of iron and lead were obtained in the study of E. coli $(65.2 \%)$ and $E$. cloacae $(65 \%)$.

\section{Conclusion}

Summing up the results of the research, we should note that all the studied microorganisms extracted from rat intestinal microbiota had relatively equal resistance values, and the level of essential elements biotoxicity had high values, which, in our view, is primarily due to the lack of detoxification mechanisms in the investigated strains, because these elements are actively involved in metabolic processes and are part of enzymes, therefore excessive concentrations (over the capacity to deposit) lead to cell death.

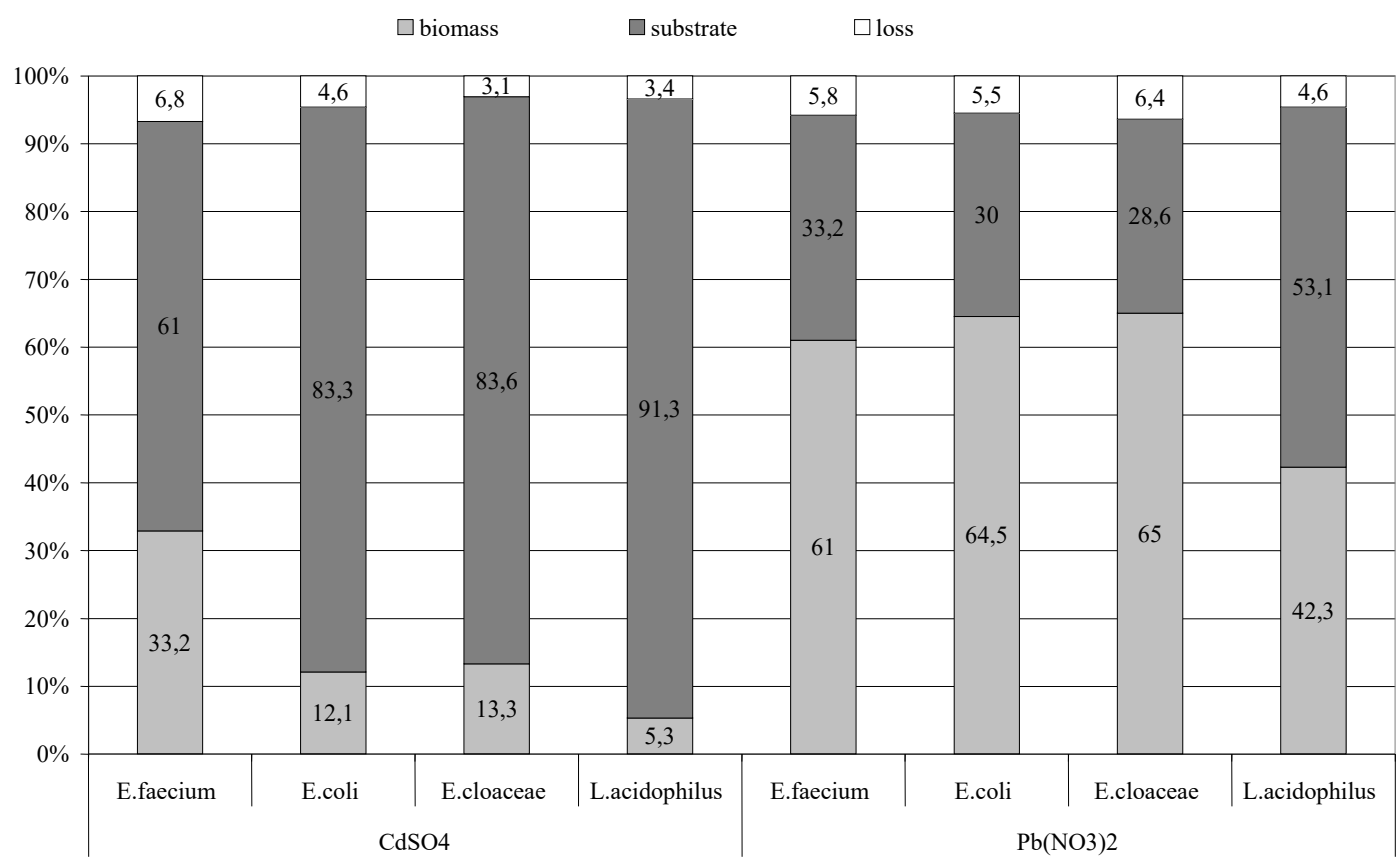

Figure 1. Bioaccumulation of heavy metal ions from liquid substrates by the representatives of optionally anaerobic intestinal microbiota in rats 
Biotoxicity of xenobiotics is patchy in the painting of manifestations: so, cadmium cations have a pronounced bactericidal effect, whereas cations of lead in salts with a different anionic component have a level biotoxicity less than the essential elements, which, as we suppose, is linked to the mechanism of detoxification (sorption of an element on the surface of cells in biologically inactive form) like the mechanisms of detoxification in probiotic strains of bacteria of the genus Bacillus [5].

Ex-libris $[1,6]$ it is known that the main manifestation of toxicity on microorganisms is the delay of their growth and reproduction, as well as a demonstration of the bactericide abilities of heavy metal ions, which leads to the death of microorganisms. It should be noted that microorganisms when interacting with heavy metal ions are able to accumulate them. Microorganisms accumulate metals for a variety of reasons. In one case, they can use metals as sources of micronutrients, energy, or electron acceptors. Oxidizing reduced compounds of metals, at least, some microorganisms can extract useful energy and reducing ability. Reducing oxidized compounds of metals, a number of microbes carry out the process, which is apparently a form of breathing. In other cases, the accumulation of heavy metal ions by microorganisms might be a way of their detoxification, which is carried out by means of the specific binding of metal with special polymers, probably synthesized under influence of heavy metals when they act as stressors. As a result of redox processes, microorganisms convert metals from the ionic form into metallic one, forming complexes with organic and inorganic compounds.

Analysis of the literature on accumulation of the studied metals proves that many microorganisms are able to sorb these elements in large quantities, for example, a strain of $Z$. ramigera is able to accumulate up to $170 \mathrm{mg}$ of copper at $1 \mathrm{~g}$ of dry biomass, and cadmium ions up to $16.3 \mathrm{mg} / \mathrm{g}$ [7].

The ability to accumulate metals was found among opportunistic microorganisms. So, strains of Escherichia coli, Aeromonas hydrophila, Klebsiella oxycota, and Enterobacter cloacae accumulate lead ions in quantity of $735 \mathrm{mg} / \mathrm{g}, 565 \mathrm{mg} / \mathrm{g}, 52.5 \mathrm{mg} / \mathrm{g}$ and $156 \mathrm{mg} / \mathrm{g}$ of dry weight, respectively. Others, such as microorganisms of the genus Staphylococcus, accumulate a wide range of metals (mercury, lead, zinc, cobalt, copper, and chromium) and are not characterized with selectivity. $P$. aeruginosa sorbs lead ions up to $45 \mathrm{mg} / \mathrm{g}$ of dry weight of biomass, cadmium ions in quantities of $12 \mu \mathrm{g} / \mathrm{g}$ [8].

$P$. fluorescens strain accumulates copper ions in quantities up to $500 \mathrm{mg} / \mathrm{g}$ of dry biomass [9], and the strain of $P$. mendocina sorbs copper in quantities up to $558 \mathrm{mg} / \mathrm{g}$ of dry biomass and cadmium to $0.75 \mathrm{mg} / \mathrm{g}$ of dry biomass [10].

$P$. pseudoalcaligenes reasonably well accumulates lead and copper ions, their number reach $271.7 \mathrm{mg} / \mathrm{g}$ and $46.8 \mathrm{mg} / \mathrm{g}$ of dry biomass, respectively $[11,12]$.

Some microorganisms of the genus Citrobacter can sorb ions of lead, zinc, and cadmium in the amount of $11.8 \%, 84.3 \%$, and $33.4 \%$, respectively [13].

From the above, we can conclude that microorganisms have a unique ability to sorb various heavy metals. Accumulation rate is directly associated not only with the depositing and detoxification characteristics of the strains but with individual features of the representatives of prokaryotes.

The work was supported by a grant in the field of scientific and scientific-technical activity of the Orenburg region (№38 from 31.07.2018)

\section{References}

1. A.N. Sizentsov, T.A. Galchenko, Yu.I. Martynovich, Scientific notes of Bauman Kazan State Academy of Veterinary Medicine 216, 303-307, (2013)

2. A.N. Sizentsov, O.V. Kvan, S.V. Notova, T.A. Galchenko, Herald of restorative medicine 2, 66-75, (2014)

3. E. Cholewińska, K. Ognik, B. Fotschki et al., PLoS One 13(5), e0197083, doi: 10.1371/journal.pone.0197083, (2018)

4. S. Fang, Z. Zhuo, X. Yu, H. Wang, J. Feng, J Trace Elem Med Biol. 47, 12-20, doi: 10.1016/j.jtemb.2018.01.002, (2018)

5. A. Ghonimy, DM. Zhang, MH. Farouk, Q. Wang, Int J Mol Sci. 19(4), E1008, doi: 10.3390/ijms19041008, (2018)

6. Y. Jin, S. Wu, Z. Zeng, Z. Fu, Environ Pollut. 222, 1-9, doi: 10.1016/j.envpol.2016.11.045, (2017)

7. X.L. Meng, S. Li, C.B. Qin et al., Ecotoxicol Environ Saf. 160, 257-264, doi: 10.1016/j.ecoenv.2018.05.050, (2018)

8. M.B. Reddy, S.M. Armah, J Agric Food Chem. 66(24), 6213-6218, doi: 10.1021/acs.jafc.8b01758, (2018)

9. K.P. Vadalasetty, C. Lauridsen, R.M. Engberg et al., BMC Vet Res. 14(1), 1, doi: 10.1186/s12917-0171323-x, (2018)

10. H. Yang, J. Wang, Z. Lv et al., Ecotoxicol Environ Saf. 159, 1-9, doi: 10.1016/j.ecoenv.2018.04.053, (2018)

11. N. Yin, R. Gao, B. Knowles et al., Sci Total Environ. 651(Pt 1), 1489-1494, doi: 10.1016/j.scitotenv.2018.09.312, (2018) 